\title{
Are you Healthy and Happy? A Cross-Sectional Study on Mental Health and Happiness among University Student- Athletes in Malaysia
}

Shyronita Julis, Patricia Pawa Pitil, Wan Juliana Emeih Wahed

To Link this Article: http://dx.doi.org/10.6007/IJARBSS/v11-i3/8926 DOI:10.6007/IJARBSS/v11-i3/8926

Received: 10 January 2021, Revised: 13 February 2021, Accepted: 16 February 2021

Published Online: 26 March 2021

In-Text Citation: (Julis et al., 2021)

To Cite this Article: Julis, S., Pitil, P. P., \& Wahed, W. J. E. (2021). Are you healthy and happy? A Cross-Sectional Study on Mental Health and Happiness among University Student-Athletes in Malaysia. International Journal of Academic Research in Business and Social Sciences, 11(3), 1321-1331.

Copyright: (c) 2021 The Author(s)

Published by Human Resource Management Academic Research Society (www.hrmars.com)

This article is published under the Creative Commons Attribution (CC BY 4.0) license. Anyone may reproduce, distribute, translate and create derivative works of this article (for both commercial and non-commercial purposes), subject to full attribution to the original publication and authors. The full terms of this license may be seen at: http://creativecommons.org/licences/by/4.0/legalcode

Vol. 11, No. 3, 2021, Pg. 1321 - 1331

Full Terms \& Conditions of access and use can be found at http://hrmars.com/index.php/pages/detail/publication-ethics 


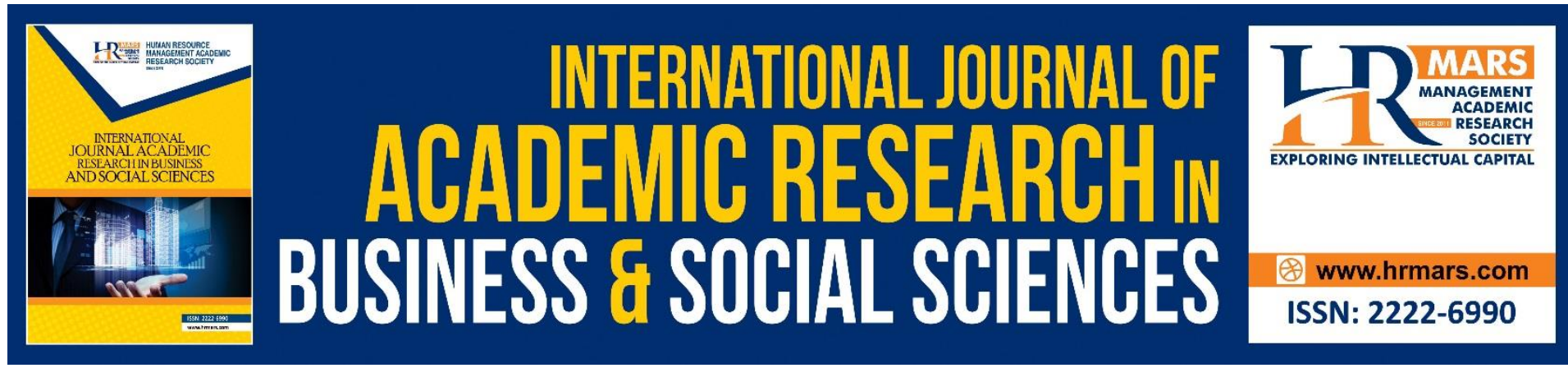

\title{
Are you Healthy and Happy? A Cross-Sectional Study on Mental Health and Happiness among University Student-Athletes in Malaysia
}

\section{Shyronita Julis ${ }^{1}$, Patricia Pawa Pitil ${ }^{2}$, Wan Juliana Emeih Wahed $^{3}$}

1,2 Faculty of Sports Science \& Recreation, Universiti Teknologi MARA, Cawangan Sarawak 94300 Kota Samarahan, Sarawak, Malaysia, ${ }^{3}$ Faculty of Art \& Design, Universiti Teknologi MARA, Cawangan Sarawak, 94300 Kota Samarahan Sarawak, Malaysia

Email: shyronitajulis@gmail.com, patriciapawa@uitm.edu.my,wanjuliana@uitm.edu.my

\begin{abstract}
Despite its successful academic achievement, Malaysian students suffer from poor mental health. Various sources of poor mental health reported and playing dual roles as studentathletes could be more stressful. How happy these students are yet to be explored with their mental health. Thus, this study aimed to explore the mental health and happiness among university student-athletes and their differences with demographic variables. Participants were university student-athletes who competed in Sukan Institut Pengajian Tinggi (SUKIPT) $(\mathrm{N}=364)$. A stratified sampling technique was employed in selecting the participants through self-administered questionnaires. The instruments used were the General Health questionnaire (GHQ) and Oxford Happiness Questionnaire (OHQ) to measure mental health and happiness of the participants. Findings revealed that the athletes have a moderate mental health and considerable happiness. The female athletes were significantly happier than the male athletes $(p<.05)$, while the mental health exhibited no significant difference $(p>.05)$. The results also revealed no significant relationship between mental health and happiness ( $p$ $>$.05). Higher institutions should pay attention to the student-athletes' sports and academic demand to prevent mental health issue.
\end{abstract}

Keywords: Happiness, Mental Health, University Athletes

\section{Introduction}

Positive affect, lack of negative affect and a great life satisfaction is a combination of a happiness (Argyle, Martin \& Lu, 1995). As the world is globally changing in terms of physical health, the focus has shifted to the health of mind. The studies of positive psychology have been the attention of many psychologists and mental health specialists (Suldo, Savage \& Mercer, 2014; Casellas-Grau, Font \& Vives, 2014). Mental health has become a highlighted topic worldwide. With the various cases of mental disorder, World Health Organization (WHO) maintains that health is not only an absence of disease but also the state of physical health as well as mental and social well-being (WHO, 2015). It is described as which an 
individual realizes his or her own abilities, can cope with the normal stresses of life, can work productively and is able to make a contribution to his or her community. The organization predicted that mental health would be the burden of health in 2030. Globally, over 800000 people die due to suicide every year and suicide is the second leading cause of death in 15 to 29-year-olds (World Health Statistics, 2018). Suicide is closely related to an unhealthy mental. Most of the cases occur in low and middle-income countries. Mental disorders and harmful use of alcohol has contributed to many suicides around the world. The importance of physically and mentally healthy has become a major concern as overall health nowadays.

In addition, mental health is expected to be a major health issue after cardiovascular disease among Malaysian in the year 2020 (Ministry of Health, 2019). National Health and Morbidity Survey (2015) also reported that $29 \%$ of adults from age 16 years and above are suffering from various mental illnesses, including depression. Depression is chronic untreated stress (Khan \& Khan, 2017). University life is the phase where the young adults enter adulthood, where they experienced a vast transition from home to independent living. Stress is commonly associated with the life of university students. University students experience a substantial amount of change where they transited form high school setting to a more selfcontrol independent thinking and learning. A process that needs these students to cope with the psychological changes could lead to stress (Stallman, 2010; Vazquez, Otero, \& Diaz, 2012) during which, the major leading causes of stress were due to academic stress and time management. Despite its successful academic achievement, Malaysian students suffer from poor mental health (Mey \& Yin, 2015; Ministry of Health, 2016), which is very worrisome.

The relationship between happiness and mental health among university athletes is the aim of this study. Athletes were demonstrated have better mental health and happiness compare to non-athletes (Majlesi, Nekooei \& Nekouei, 2014). Participation in sports may bring positive effect on mental health and happiness. In addition, physical activity is one of the factors influencing health. As athletes are well-known as those who will be very active in the university due to training and competition, exploring the relationship of these dependent variables would be an eye-opener to understand further on this population. According to Malaysian Psychiatry Association, one of the ways preventing depression is by engaging in regular exercise. As university athletes are those who are dealing with managing time between sporting activities and academic requirement, they could be more prone to stress or any other mental illness. Few cases have reported that depression does occur among university students in Malaysia with female students exhibited a greater risk (Md. Ashraful, Wah, Wen, Claire \& Adina, 2018). In their study, it was found out that those with low physical activity tend to have a greater risk of depression. Regular participation in physical activity has positive effects on physical, social, and mental health (Janssen \& LeBlanc,2010; Grosclaude \& Ziltener, 2017). In addition, it reduces the risk of developing chronic diseases, enhances the quality of life and well-being, and improves cognitive functioning (Penedo \& Dahn, 2005).

Ministry of Higher Education (MoHE) in collaboration with Higher Education Institutions Sports Council take the initiative to organize Sukan Pengajian Tinggi (SUKIPT) since 2012. It is organized biennially with the alternate of Malaysia Education Institutes Sports Carnival every other year. It is one of the platforms for MoHE to integratedly develop sports at Higher Education Institutions, national and international levels.

Therefore, the study general objective is to measure the relationship between happiness and mental health and specifically explore those differences by demographics among university athletes. 


\section{Method \\ Participants}

Athletes who were competing in the SUKIPT were the participants of this crosssectional study. From the total population of 7000 athletes (www.sukipt.com.my), the minimum sample size required was $N=364$ (Krejcie \& Morgan, 1970). A stratified random sampling technique was utilized to gather the participants. A stratified random sampling is a type of probability sampling that requires the division of a population into a smaller group, strata, which in this study, male and female were recruited equally, and the type of sports also was taken into consideration.

An approval to conduct the study from the organizer was obtained prior to the data collection. Permission was also sought from the coaches. The study protocol was approved by the faculty's ethic committee to ensure ethical principles. The participation was voluntarily and anonymous. In the self-administered survey, the participants were briefed on the purpose of the study in a meeting. Verbal consent was received from all the participants. The questionnaires were in the following order: demographic profile (gender, age, type of sports, education level and years of experience in sports), General Health Questionnaire and Oxford Happiness Questionnaire. The completion of the questionnaires took approximately 15 to 20 minutes. The participants were required to provide honest responses and they were allowed to ask any question, if there is any, when answering the questionnaire.

\section{Instruments}

\section{a) A measure of mental health}

The General Health Questionnaire (GHQ) was employed to measure the mental health of the participants. It is a measure of current mental health since its development by Goldberg and Hillier (1979) and has been extensively used in different settings and different cultures. It serves as a self-administered tool for assessment of general mental health. It consisted of 12self-rated items which ask about the presence of a range of symptoms during the past months. The scoring method of a 4-point Likert scale ranging from Often, Sometimes, Seldom to Never (1-2-3-4 or 4-3-2-1) is used which summed up the points to a total score ranging between 12 and 48, with a higher score indicating poorer mental health. This instrument is reported as highly reliable for general population (Pevalin, 2000).

\section{b) A measure of happiness}

Happiness was measured by using the Oxford Happiness Questionnaire (OHQ). This questionnaire has 29 items developed by Hills and Argyle (2002). The items were rated using a 6-point scale, from 1 (strongly disagree) to 6 (strongly agree). The happiness score ranges from 29 to 174; higher scores indicate higher happiness. This instrument is reported as highly reliable and valid for measuring happiness (Hadinezhad \& Zaree, 2009).

\section{Data Analysis}

The data collected were analyzed by using the Statistical Package for Social Science (SPSS) version 22.0. Internal consistency was assessed by using Cronbach's alpha and showed a high reliability; mental health, $\alpha=.750$ and happiness, $\alpha=.873$. An $\alpha$ value greater than 0.6 is desirable reliability (Lance, Butts \& Michels, 2006). Normal distribution was tested by using the skewness and kurtosis analysis which revealed that the data for all the variables measures were normally distributed; skewness $=-.236$ and -.101 and kurtosis $=-.260$ and -.864 respectively for mental health and happiness. The skewness and kurtosis ranges between -1 
to was and indicator of a normal distribution (Kim, 2013). Equal variances assumption was also met for all the variables measured by gender, age groups, study level, type of sports and years of sporting experience.

Descriptive data were presented using mean and standard deviation $(M \pm S D)$, frequencies, and percentages. The Independent Sample t-test was performed to measure the difference in mental health and happiness between male and female participants, age groups and type of sports. One-way analysis of variance was employed to assess the differences between study level and years of sporting experience in both measures. In evaluating the relationships, the Pearson correlation test was employed. The statistical significant was set at $.05(p<.05)$.

\section{Result}

A total of $N=364$ participants completed the questionnaires. The distribution of male and female participants was almost equal; $52.2 \%(n=190)$ male and $47.8 \%(n=174)$ female (equal variance was met) as presented in Table 1. Majority of them aged from 18 to 23 years old $(80.3 \%)$ and some were above 24 years old (18.7\%). For the level of education, $46.4 \%$ were diploma and $49.2 \%$ were undergraduates. Few were certificate (1.9\%) and master degree students (2.5\%). Majority of them were playing for team sports (82.7\%) and only $17.3 \%$ were individual sports athletes. In years of sporting experience, $43.1 \%$ has experience of 1 to 3 years, while $33.2 \%$ were 3 to 5 years of experience. For experience less than a year, there were $23.6 \%$ of participants.

Table 2 shows the mean and standard deviation of mental health items. Item 'Feeling that you had not made good use of time' $(2.63 \pm 0.769)$ and 'Feeling that you were not decisive' $(2.63 \pm 0.763)$ score the highest among the items. The lowest mean score is the item 'Feeling happy in general' $(1.71 \pm 0.752)$.

Table 2 represents the overall score for both dependent variables of the study. The mean mental health score was $27.17 \pm 3.90$ (min: 16 and max: 37 ) and mean happiness score was $126.46 \pm 14.57$ ( $\min : 94$ and max: 145). In comparison between gender, there was a significant difference in happiness score between male and female participants; $t$ (362) = $3.159, p<.05$. However, the mean score for mental health was similar between male and female participants $(p>.05)$.

The result of a Pearson correlation in Table 3 indicates that the mental health score was not significantly correlated with happiness score $(p>.05)$. 
Table 1. Demographic Profile of the Participants $(N=364)$

\begin{tabular}{ll}
\hline Demographic & $n(\%)$ \\
\hline Gender & $190(52.2)$ \\
Male & $174(47.8)$ \\
Female & \\
Age (years) & $293(80.3)$ \\
$18-23$ & $68(18.7)$ \\
24 and above & \\
Study level & $7(1.9)$ \\
$\quad$ Certificate & $169(46.4)$ \\
Diploma & $179(49.2)$ \\
Bachelor's degree & $9(2.5)$ \\
$\quad$ Master's degree & \\
Type of sports & $63(17.3)$ \\
Individual & $301(82.7)$ \\
Team & \\
Years of sporting experience & $86(23.6)$ \\
Less than a year & $157(43.1)$ \\
1 to 3 years & $121(33.2)$ \\
More than 4 years &
\end{tabular}

Table 2. Descriptive Statistics of Mental Health among the Participants

\begin{tabular}{cll}
\hline No & Variables & $M \pm S D$ \\
\hline & Mental health (overall score) & $27.17 \pm 3.90$ \\
Items & & \\
1 & Feeling that you had not made good use of time & $2.37 \pm 0.769$ \\
2 & Feeling that you were not decisive & $2.37 \pm 0.763$ \\
3 & Feeling that you had suffered from pressure & $2.54 \pm 0.810$ \\
4 & Feeling that you could not overcome your own & $2.60 \pm 0.816$ \\
& difficulties & \\
5 & Feeling unhappy or distressed & $2.77 \pm 0.859$ \\
6 & Able to lead a happy life & $1.72 \pm 0.704$ \\
7 & Able to face your own difficulties & $1.81 \pm 0.735$ \\
8 & Sleepless because of worrying something & $2.73 \pm 0.760$ \\
9 & Having lost self-confidence & $2.62 \pm 0.695$ \\
10 & Able to concentrate on doing anything & $1.87 \pm 0.745$ \\
11 & Feeling that you were a useful person & $1.92 \pm 0.746$ \\
12 & Feeling happy in general & $1.71 \pm 0.752$ \\
\hline
\end{tabular}

Note. Item 1, 2, 3, 4, 5, 8, and 9 uses scale 1-2-3-4 (Often-Sometimes-Seldom-Never) Item $6,7,10,11$ and 12 are reversed scores (4-3-2-1, Never-Seldom-Sometimes-Often) 
Table 3. Mean Scores of Mental Health and Happiness by Demographics ( $N=364)$

\begin{tabular}{|c|c|c|}
\hline & Mental Health & Happiness \\
\hline Overall & $27.17 \pm 3.90$ & $126.46 \pm 14.57$ \\
\hline Minimum & 16 & 94 \\
\hline Maximum & 37 & 158 \\
\hline \multicolumn{3}{|l|}{ Gender } \\
\hline Male & $27.17 \pm 3.89$ & $124.14 \pm 14.77$ \\
\hline Female & $26.87 \pm 3.77$ & $128.98 \pm 13.95$ \\
\hline$p$-value & .448 & $.001 *$ \\
\hline \multicolumn{3}{|l|}{ Age (years) } \\
\hline $18-23$ & $26.76 \pm 3.82$ & $127.69 \pm 14.66$ \\
\hline$>24$ & $27.38 \pm 3.97$ & $125.75 \pm 14.39$ \\
\hline$p$-value & .200 & .276 \\
\hline \multicolumn{3}{|l|}{ Study level } \\
\hline Certificate & $28.00 \pm 4.40$ & $115.43 \pm 9.71$ \\
\hline Diploma & $27.04 \pm 3.95$ & $127.74 \pm 14.78$ \\
\hline Bachelor's degree & $27.11 \pm 3.62$ & $125.60 \pm 14.17$ \\
\hline Master's degree & $24.33 \pm 4.90$ & $127.89 \pm 18.46$ \\
\hline$p$-value & .173 & .110 \\
\hline \multicolumn{3}{|l|}{ Type of sports } \\
\hline Individual & $26.75 \pm 4.32$ & $124.10 \pm 14.73$ \\
\hline Team & $27.09 \pm 3.73$ & $126.95 \pm 14.51$ \\
\hline$p$-value & .523 & .157 \\
\hline \multicolumn{3}{|c|}{ Years of sporting experience } \\
\hline Less than a year & $27.29 \pm 3.54$ & $126.91 \pm 12.52$ \\
\hline $1-3$ years & $27.14 \pm 3.78$ & $127.75 \pm 13.97$ \\
\hline More than 3 years & $26.69 \pm 4.11$ & $124.45 \pm 16.46$ \\
\hline$p$-value & .485 & .165 \\
\hline
\end{tabular}

PQ: Physical health; PsychQ: Psychological health; SRQ: Social relationship; EnvQ: Environment

Table 4. Relationship Between Mental Health and Happiness of the Participants

\begin{tabular}{lll}
\hline Variables & Happiness & $p$-value \\
\hline Mental health & $r=-.048$ & $.363^{\ddagger}$ \\
\hline${ }^{\ddagger} p>.05$ & &
\end{tabular}

\section{Discussion}

In this study, the mental health of the university athletes is considered moderate, based on the score, $27.17 \pm 3.90$. The maximum score of the instrument is 48 , and a higher score indicates poorer mental health. In detail of the score per item, the item 'feeling of not made of good use of time' and 'not decisive' were lowest amongst the items rated with scale often to never $(1-4)$, revealing that the university athletes are struggling with time management and also decision-making. As student-athletes are known to be highly active in training and competition, balancing these with their academic demand could be exhausting. 
Even though studies have concluded that physical activity leads to improve mental health (Lathia, Sandstorm, Mascolo \& Rentfrow, 2017;) and athletes are mentally healthier and happier if compared to the non-athletes (Godarzi \& Hemayattalab, 2005; Hajloo \& Pezeshki, 2013), the current findings should be highlighted as a precaution of unhealthy minds among this population. While the item 'Feeling happy in general' was the lowest amongst the items rated with a scale never to often $(1-4)$, revealing that the university athletes are happy in general. This is related to the overall happiness of the university athletes, which in this study, had a score of $126.46 \pm 14.57$ (maximum score of the instrument is 174). The university athletes are considerably happy in general. The present finding is similar to other study conducted among postgraduates' students in Malaysia, where a majority of the students were happy (Mohd Amirul, 2013). A qualitative study conducted among medical students by found happiness was highly influenced by money, followed by friends and family (Al-Naggar,AlKashamy, Low, Mohd Isa, Alsaror, \& Al-Naggar, 2010).

In comparing the mental health and happiness scores by demographics, there were similar distribution of scores, except for gender. The females are significantly happier than males. This is also present in other studies where females are always exhibited as happier than the males (Mohd Amirul, 2013; Perneger, Hudelson \& Bovier, 2004). The female athletes being happier might be influenced by their sports participation. In a study by Goudarzi and Hemayattalab (2005), sports participation affects the females' behaviour and temper, decrease their stress and anxiety and improve self-confidence. Engaging in sports benefits a lot of the female athletes in this study. All the participants were university athletes; thus, it can be concluded that athletes have acceptable happiness. This result is supported by a study conducted among females in comparing athletes and non-athletes, whereby the athletes were revealed to be happier than the non-athletes (Mostafai, 2012). They demonstrated more positive emotion and have a greater satisfaction that can lead to a happier life (Mostafai, 2012). In addition, good health is reported to be associated with happiness (Pier'o, 2006), which would explain present study's population of a happier state as athletes regularly engage in physical activity and exercise to boost their health status. Those who were highly active would exhibit greater happiness (Lesani, Mohammadpoorasl, Javadi, Ansari \& Fakhari, 2016).

In examining the relationship between mental health and happiness, the result revealed no significance. The mental health of university athletes is not related to their happiness. Although athletes are always assumed as physically healthy, their mental health does not signify their happiness. Therefore, this study warrants further exploration on the university student-athletes' happiness and mental health.

\section{Conclusion}

The results of this study suggest that university athletes have moderate mental health and considerable happiness. By gender comparison, mental health is similar in demographics assessed and same goes to happiness score, except for gender. Interestingly, female university athletes are happier than males. Even though there was no relationship between mental health and happiness, their physical activity could influence their happiness state. Precaution on time management and decision-making among these athletes should be paid attention to, so that the struggle of balancing sports with their academic demand would not lead to an unhealthy mental state, which is stress and eventually being at risk of depression. Institutions are recommended to be aware of the mental health of this population to ensure it is aligned with their physical health. Moreover, intervention studies to examine the effects 
of behavioral intervention on mental health of Malaysian university student-athletes appear to be merited. Future studies could benefit from exploring these dependent variables including the possible factors related to university athletes such as academic performance, scholarship, or year of study.

This study adds to the theoretical understanding of the link between mental health and happiness. Athletes who are physically fit are usually not mentally fit. Although it is well documented that physical fitness and mental health are correlated this was not the case in this study. As a result, factors including athletic background and gender should be factored into the framework to fully comprehend the relationship.

\section{Acknowledgements}

The authors express their thanks to the SUKIPT 2018 organizer, coaches, and athletes for the kind co-operation and the faculty's research ethics committee for the approval to conduct the study. The researchers have no conflict of interest.

\section{References}

Argyle, M., Martin, M. \& Lu, L. (1995). Testing for stress and happiness: the role of social and cognitive factors. Stress and Emotion, 15, 173-187.

Al-Naggar, R. A., Al-Jashamy, K. A., Low, W. Y., Mohd Isa, Z., Alsaror, M. I., \& Al-Naggar, A. G. (2010). Perceptions and opinion of happiness among university students in a Malaysian university. ASEAN Journal of Psychiatry, 11(2), 198-206.

Casellas-Grau, A., Font, A., \& Vives, J. (2014). Positive psychology interventions in breast cancer. A systematic review. Psychooncology, 23(1), 9-19.

Grosclaude, M., \& Zilterner, J. L. (2010). Benefits of physical activity. Revue Médicale Suisse, 658, 1495-1498.

Goudarzi, M., \& Hemayattalab, R. (2005). Comparison of happiness in male and female athlete students of Tehran University. Harakat, 25, 43-52. Goldberg, D. P \& Hillier, V. F. (1979). A scaled version of the General Health Questionnaire. Psychological Medicine, 9, 139145.

Hadinezhad, H., \& Zaree, F. (2009). Reliability, validity and normalization of the Oxford Happiness Questionnaire. Psychological Research, 12(1-2), 62-77.

Hajloo, N., \& Pezeshki, H. (2013). Compare happiness, psychological tenacity, and sensation seeking among athletes and no athletes. Procedia-Social and Behavioral Science, 84, 1063-1066.

Hills, P., \& Argyle, M. (2002). The Oxford Happiness Questionnaire: a compact scale for the measurement of psychological well-being. Personality and Individual Differences, 33, 1073-1082.

Janssen, I., \& LeBlanc, A. G. (2010). Systematic review of the health benefits of physical activity and fitness in school-aged children and youth. International journal of behavioral nutrition and physical activity, 7(1), 1-16.Khan, S. \& Khan, R. A. (2017). Chronic stress leads to anxiety and depression. Annals of Psychiatry and Mental Health, 5(1), 1091.

Kim H. Y. (2013). Statistical notes for clinical researchers: assessing normal distribution (2) using skewness and kurtosis. Restorative Dentistry \& Endodontics, 38(1), 52-54. doi.org/10.5395/rde.2013.38.1.52

Krejcie, R. V., \& Morgan, D. W. (1970). Determining sample size for research activities. Educational and Psychological Measurement, 30, 607-610. 
Lance, C. E., Butts, M. M., \& Michels, L. C. (2006). The sources of four commonly reported cutoff criteria: what did they really say? Organisational Research Methods, 9, 202220.

Lathia, N., Sandstrom, G. M., Mascolo, C., \& Rentfrow, P. J. (2017). Happier people live more active lives: Using smartphones to link happiness and physical activity. PLOS ONE, 12(1), e0160589.

Lesani, A., Mohammadpoorasi, A., Javadi, M., Ansari, H. \& Fakhari, A. (2016). Happiness among college students: a cross-sectional web-based study among Iranian Medical students. Biotechnology and Health Sciences. In Press, e36029

Majlesi, S., Nekooei, P., \& Nekouei, P. (2014). Comparison on mental health and happiness between athletes and non-athletes. 2nd IPGM International Conference on Teacher Learning and Development at Sarawak, Malaysia, 2.

Md. Ashraful, I., Wah, Y. L., Claire, C. W. Y., \& Adina A. (2018). Factors associated with depression among university students in Malaysia: A cross-sectional study. The 2nd International Meeting of Public Health 2016 with theme "Public Health Perspective of Sustainable Development Goals: The Challenges and Opportunities in Asia-Pacific Region", KnE Life Sciences, 415-427. doi 10.18502/kls.v4i4.2302.

Mey, C., \& Yin, C. J. (2015). Mental health and wellbeing of the undergraduate students in a research university: A Malaysian experience. Social Indicators Research, 122(2), 539551. doi.org/10.1007/s11205-014-0704-9.

Ministry of Health. (2016). Press statement by Minister of Health Malaysia. Author. Retrieved from

http://www.moh.gov.my/english.php/database_stores/store_view_page/22/451.

Accessed 9 Dec 2018.

Ministry of Health. (2019). Press statement by Minister of Health Malaysia. Author. Retrieved from

https://www.moh.gov.my/moh/modules_resources/database_stores/96/337_1246. pdf. Accessed 21 March 2021

Amirul, M. R. A. R. (2013). The effect of life satisfaction and religiosity on happiness among postgraduates in Malaysia. Journal of Humanities and Social Science, 11(1), 34-38.

Mostafai, A. (2012). The comparison between athlete women and non-athlete women regarding to mental health and happiness. Annals of Biological Research, 3(5), 21442147.

National Health and Morbidity Survey. (2015). Non-communicable diseases, risk factors and other health problems. Vol II. Institute of Public Health, Ministry of Health Malaysia.

Perneger, T. V., Hudelson, P. M., \& Bovier, P. A. (2004). Health and happiness in young Swiss adults. Quality of Life Research, 13, 171-178.

Pevalin, D. J. (2000). Multiple applications of the GHQ-12 in a general population sample: An investigation of long-term retest effects. Soc Psychiatry Psychiatr Epidemio, 35, 508512.

Peir'o, A. (2006). Happiness, satisfaction, and socio-economic conditions: some international evidence. The Journal of Socio-Economics, 35, 348-365.

Penedo, F. J., \& Dahn, J. R. (2005). Exercise and well-being: a review of mental and physical health benefits associated with physical activity. Current Opinion in Psychiatry, 18(2), 189-193.

Stallman, H. M. (2010). Psychological distress in university students: A comparison with general population data. Australian Psychologist, 45(4), 249-257. 
Suldo, S. M., Savage, J. A., \& Mercer, S. H. (2014). Increasing middle school students' life satisfaction: efficacy of a positive psychology group intervention. Journal of Happiness Studies, 15(1), 19-42.Vazquez, F. L., Otero, P., \& Diaz, O. (2012). Psychological distress and related factors in female college students. Journal of American college health, 60(3), 219-225.

World Health Statistics (2018). Monitoring health for the Sustainable development goals. World Health Organization.

World Health Organization (2015). WHO definition of Health. http://www.who.int/about/definition/en/print.html. 